\title{
Cross-Sectional and Time-Series Momentum Returns and Market Dynamics: Evidence from Japan
}

\author{
Muhammad A. Cheema, Gilbert V. Nartea, and Kenneth Szulczyk
}

This Version: November 2017

\begin{abstract}
We test the behavioural theories of overconfidence and underreaction on crosssectional (CS) and times-series (TS) momentum returns in the Japanese stock markets. Both CS and TS momentum returns are large and significant when the market continues in the same state and turns into losses when the market transitions to another state, consistent with the overconfidence but not the underreaction model. We find that TS conditional momentum returns exceed conditional CS momentum returns because of its active position since TS takes a net long (short) position following UP (DN) markets while CS is a zero-cost strategy irrespective of the market state. Finally, we find no relation between idiosyncratic volatility and momentum returns which is not supportive of either the overconfidence or underreaction model but implies that idiosyncratic volatility is not a significant limit to arbitrage in Japan.
\end{abstract}




\section{Introduction}

The cross-sectional momentum trading strategy (henceforth CS), proposed by Jegadeesh and Titman (1993), consists of buying (selling) the top (bottom) decile of stocks based on the past returns of three to 12 months and holding them over the next three to 12 months. They show that this strategy generates significant momentum returns in the U.S. markets. Subsequently, Moskowitz, Ooi and Pedersen (2012) find larger momentum returns by buying (selling) different asset classes with positive (negative) past excess returns over the risk-free rate compared to the top (bottom) decile over the recent months. The literature refers to this as the time-series momentum strategy (henceforth TS). Numerous studies find momentum returns using both CS and TS strategies in various asset classes including stocks, indices, commodities, futures and currency markets (see for example, Moskowitz et al., 2012, Goyal and Jegadeesh, 2015).

Stock selection could cause TS momentum returns to exceed CS. The CS strategy buys (sells) an equal number of stocks based on the average returns over the ranking period while the TS strategy buys (sells) all stocks with positive (negative) returns over the ranking period. Therefore, the CS strategy has a net position of zero because the long and short positions would consist of an equal number of stocks. For the TS strategy, it is unlikely that the number of stocks in the long position will equal the short position because a bull (bear) market would have a greater number of stocks with positive (negative) returns, resulting in a net long (short) position. In a recent paper, Goyal and Jegadeesh (2015) show that the TS strategy outperforms the CS largely because of its net long position. They further argue that markets generally have more UP than DOWN states, which result in a net long position for the TS strategy. A higher number of stocks with positive past excess returns are bought 
relative to the negative past excess returns, and the net long position earns the corresponding risk premium in the market.

Fama and French (1996) find that risk factors cannot explain momentum returns, so research has shifted to the links between momentum returns and behavioural biases (Asem and Tian, 2010, Arena, Haggard and Yan, 2008). There are three main competing behavioural models related to momentum, the underreaction models of Barberis, Shleifer and Vishny (1998) and Hong and Stein (1999), and the overconfidence and self-attribution model of Daniel, Hirshleifer and Subrahmanyam (1998). Barberis et al. (1998) argue that investors underreact to new public information, which slows the information's impact on stock prices. Thus in this model momentum returns arise from investors' underreaction to the new public information. Hong and Stein's (1999) model posits that momentum profits originate from the interactions between two investor groups: news watchers and momentum traders. The news watchers rely on private information for their trades while momentum traders rely on historical data and chase trends. The model also assumes that private information is incorporated into stock prices slowly. This leads to positive autocorrelation in prices and attracts the attention of momentum traders who overreact to the price continuations that eventually reverse in the long run. Finally, the model of Daniel et al. (1998) suggest that momentum is driven by investor overconfidence and self-attribution bias. They hypothesize that overconfident investors underreact to public information and overreact to their private information. Once an investor witnesses public information that affirms his or her private information, the investor's overconfidence strengthens after a trade. For example, overconfidence rises when good (bad) news arrives following a buy (sell) trade. However, overconfidence weakens little from the contradictory public news because of self-attribution 
bias. Investors attribute confirming news to their personal ability and contradictory news to luck, which induces momentum returns in the short run.

Both the models of Hong and Stein (1999) and Daniel et al. (1998) predict a relation between momentum returns and market states. Hong and Stein (1999) suggest that lower investor risk aversion leads to greater underreaction to information, and hence to stronger momentum returns. To the extent that UP markets lead to lower risk aversion among investors, Hong and Stein's model implies greater momentum returns during UP than DN markets. Daniel et al.'s (1999) model predicts that investor overconfidence will increase when the market continues in the same state than when it transitions to a different state. Therefore in as much as momentum is driven by overconfidence, momentum returns should be higher when the market either continues UP (ie., UP/UP) or DOWN (ie., DN/DN), than when it transitions UP or DOWN (ie., DN/UP or UP/DN). The model of Barberis, et al. (1998) does not make any explicit prediction on the relation between momentum returns and market states.

All the three models also predict a positive relation between momentum returns and idiosyncratic volatility (IV). To the extent that IV is a proxy for firm-specific information, both the models of Hong and Stein (1999) and Barberis et al (1998) predict higher momentum returns for stocks with high IV. On the other hand, Daniel et al. (1998) presume that investors will become more overconfident in nebulous situations where "feedback on their information or decisions is slow or inconclusive than where feedback is clear and rapid" (p. 1859). Therefore, this presumption implies higher momentum returns for hard to value stocks. To the extent that high IV stocks are hard to value, Daniel et al.'s (1998) model also suggest a positive relation between momentum returns and IV. 
Asem and Tian (2010) test the predictions of Hong and Stein (1999) and Daniel et al. (1998) by conditioning momentum returns on market dynamics. They classify the market state as UP/UP (DN/DN) if the lagged 12-month (from $t$-11 to $t$ ) and subsequent month $(t+1)$ market returns are positive (negative). Furthermore, they define UP/DN (DN/UP) market state if the lagged 12-month return is positive (negative) and subsequent month market return is negative (positive). They find greater and significant momentum returns in U.S. markets when both lagged and subsequent market returns have identical signs, consistent with the prediction of Daniel et al. (1998) but not with Hong and Stein (1999) but they do not find supporting results in Japan. However more recently, employing several screens on his dataset, Hanauer (2014) documents momentum returns in Japan when the market continues in the same direction, UP or DN, consistent with the results of Asem and Tian (2010) for the U.S. markets. ${ }^{1}$ Both studies by Hanauer (2014) and Asem and Tian (2010) employ CS momentum. In this study, we also examine the relation between momentum returns and market states in Japan using the TS strategy.

Arena et al. (2008) examine the relation between momentum returns and IV in U.S. stocks and find a positive relation, consistent with predictions of the behavioural models of Barberis et al. (1998), Hong and Stein (1999) and Daniel et al. (1998). Their results also support the suggestion that the momentum anomaly persists because of limits to arbitrage, with IV as an important limit (Shleifer and Vishny, 1997). However, McLean (2010) finds no relation between momentum returns and IV and disputes the results in Arena, Haggard, and Yan (2008). McLean (2010) shows that the positive relation between momentum returns and

\footnotetext{
${ }^{1}$ For example, Hanauer (2014) excludes stocks which are not quoted in local JPY or ISIN country code other than 'JP'. He also eliminates non-common equity stocks, by searching for suspicious words in the firm name which indicate that the firm is more likely a duplicate, preferred stock, depository receipts, warrants, and trusts, etc.
} 
IV shown in Arena, Haggard, and Yan (2008) was a result of the exclusion of most high IV stocks, such as small size and low price stocks, from their sample. Since all the three models predict a positive relation between momentum returns and IV, we cannot differentiate between these models based on our test of momentum returns and IV. However, we can differentiate between these three models once we condition momentum returns on market states. We examine the relation between momentum returns and IV to verify if IV is an important limit to arbitrage in Japan.

We chose Japan since it is one of the world's top three economies and the Tokyo Stock Exchange is the third largest in the world by market capitalization. We test the predictions of the three behavioural models using both CS and TS momentum strategies. As Goyal and Jegadeesh (2015) suggest that the TS strategy yields higher momentum returns largely because of its net long position, we also test whether conditional TS returns exceed conditional CS returns. In addition, we test the efficacy of buy-and-hold (BH), re-balanced (RB) and Winners-minus-Losers (WML) portfolios to determine which portfolio strategy generates higher momentum returns. Finally, we examine the relation between IV and both CS and TS momentum returns to determine if IV is a significant limit to arbitrage in Japan.

Our results show that CS momentum returns in Japan are large and significant in market continuations but turn negative during market transitions affirming the results reported earlier in Hanauer (2014). More importantly, we show that the same relation between momentum returns and market states also holds for TS momentum returns. Therefore, our results are supportive of Daniel et al.'s model but not of Hong and Stein's. Our results are also consistent with those of Goyal and Jegadeesh (2015) with conditional TS momentum returns exceeding those of the CS strategy. We report TS momentum returns of $2.24 \%(3.43 \%)$ per month when the market continues in the UP (DN) state which exceeds the 
CS momentum returns of $2.07 \%(2.51 \%)$ per month. The TS strategy exceeds CS because the former takes a net long (short) position following UP (DN) markets which generate greater TS momentum returns. This is again consistent with Daniel et al. (1998) since a subsequent increase (decrease) after a buy (sell) trade further enhances investor overconfidence. Our results suggest that the TS strategy outperforms the CS not only because of its net long position as argued by Goyal and Jegadeesh (2015) but also because of its net short position following DN markets, consistent with the findings of Cheema, Nartea and Man (2017) in the U.S. markets. Finally, we find no relation between momentum returns and IV, consistent with McLean (2010) which implies that IV is not a significant limit to arbitrage in Japan.

Our paper makes three contributions to the extensive momentum literature. First we explicitly show that the behaviour of TS momentum returns, like CS momentum returns in earlier studies, is more consistent with Daniel et al.'s overconfidence and self-attribution model than the underreaction model of Hong and Stein. Second, we show that TS momentum returns exceed CS returns in Japan not only because of its net long position as argued by Goyal and Jegadeesh, but also because of its net short position. Third, we show that similar to the U.S., IV is not a significant limit to arbitrage in Japan.

Section II describes the data and methodology. Section III shows the empirical findings and explains the results. Section IV provides the robustness tests, and the last section concludes the study.

\section{Data and Methodology}

\section{A. Data}

The sample consists of all domestic common stocks listed on Japanese stock exchanges, and the stocks are denominated in Japanese Yen. The sample includes stock returns, market size (MV), trading volume, stock price, and the Fama-French risk factors 
from the Fama-French library. The data comes from DataStream International, and starts in January 1990 and ends in December 2014, as the Fama-French Data library has risk factors for Japan only from July 1990.

Following Ince and Porter (2006), Griffin, Kelly and Nardari (2010), and Schmidt, Von Arx, Schrimpf, Wagner and Ziegler (2014), we apply several screens to improve the quality of the dataset. ${ }^{2}$ Furthermore, following Chui, Titman and Wei (2010), we minimize the impact of outliers by setting returns greater (less) than $100 \%(-95 \%)$ to $100 \%(-95 \%)$. We adopt the procedures from Chui et al. (2010) to fix the problems of zero returns in DataStream. Zero returns could indicate no trading because DataStream carries the return index forward to the next period. The stock has a zero return if trading volume is available for that stock between $t$ and $t-1$ months. For missing trading volume data, the sample excludes zero returns. Finally, all stocks during the formation period must have at least an 8- (13-) month history to calculate stock returns of the re-balanced and buy-and-hold momentum (winner-minus-loser) portfolios. The sample consists of 5,069 stocks after the screening process eliminates 110 stocks. The sample period begins with 1,186 stocks and ends with 3,499 stocks.

Table 1 shows the summary statistics. The Nikkei225 has an average return of $0.008 \%$ per month with a maximum of $20.066 \%$ and a minimum of $-23.827 \%$ while market returns average $0.208 \%$ with a maximum of $25.59 \%$ and a minimum of $-17.43 \%$. We report a negative risk premium with the risk-free rate exceeding the returns of both the market and the Nikkei225 with a mean of $0.244 \%$ and a maximum of $0.68 \%$ and a minimum of zero. Finally, the small-minus-big size factor (SMB) average almost zero at $-0.028 \%$ with a maximum of

${ }^{2}$ Please refer to a list of generic filter rules to exclude non-common equity securities summarized in Table A1 of Hanauer (2014). 
$12.99 \%$ and a minimum of $-11.15 \%$ while the high-minus-low book to market factor (HML) has a mean of $0.419 \%$ with a maximum of $10.08 \%$ and a minimum of $-13.82 \%$.

\section{[Table 1 about here]}

Table 1, Panel B shows the correlation between variables. As expected, the stock market returns of the full sample correlate highly with the Nikkei225. However, the highminus-low (HML) market value negatively correlates with the Nikkei225 Index and market returns. Furthermore, the small-minus-big size factor positively correlates with market returns and negatively correlates with the risk-free interest rate.

\section{B. Momentum Returns Methodology}

We use three different methods to construct portfolios: rebalanced (RB), buy-andhold (BH), and winners-minus-losers (WML). RB and BH use the methodology of Jegadeesh and Titman (1993). For CS momentum returns, all stocks are ranked in ascending order based on their past 6-month returns (from $t-6$ to $t$-1). Then the stocks are sorted into 10 portfolios. The portfolio P1 holds the loser stocks while portfolio P10 has the winner stocks. We skip a month between the ranking and holding periods to mitigate the bid-ask bounce effect. The portfolios are kept for six months (from $t+1$ to $t+6$ ), skipping month $t$. Momentum returns equal the difference between P10 - P1.

For BH portfolios, following Jegadeesh and Titman (1993) we calculate momentum returns at the end of the holding period i.e., $t+6$. For example, the 6-month holding period returns of a BH portfolio with 6-month formation period that was formed in July 2014 based on formation period returns from December 2013 to May 2014 (skipping June 2014) will be calculated from July 2014 to December 2014. For RB portfolios, we rebalance the portfolios every month. For example, for 6-month formation and 6-month holding period, we buy (sell) 1/6 stocks of the portfolios that were formed during the past 6 months. Therefore, at every 
month $t+1$, the portfolio formed 6-months ago is closed. We calculate value-weighted returns for CS momentum strategy to reduce the impact of small size stocks. ${ }^{3}$

The third method of constructing portfolios referred to as winners-minus-losers (WML) employ the methodology of Carhart (1997) and Fama and French (2012). At the end of each month $t$, all stocks are ranked on their past, cumulative, 11-month returns (from $t$-11 to $t-1$ ) and divided into three portfolios. We use the bottom $30 \%$ as the loser (L), middle $40 \%$ as the medium (M), and top $30 \%$ as winner (W) portfolio. We use the lagged performance of the biggest $90 \%$ of the stocks to define the cut-off points for L, M and W portfolios. Meanwhile, portfolios are sorted further by firm size. The small (S) portfolios hold the bottom $10 \%$ market capitalization while the big (B) contains the top 90\%. Thus, the WML methodology constructs six value-weighted portfolios: small/losers (S/L), small/medium (S/M), small/winners (S/W), big/losers (B/L), big/medium (B/M) and big/winners (B/W). The value-weighted zero-cost portfolios are formed by buying (selling) the decile of stocks with the highest (lowest) 11-month lagged returns. A month is skipped between the formation and holding periods, and portfolios are then held for one month $(t+1)$. The WML return equals the average returns of the two winners $(\mathrm{S} / \mathrm{W}, \mathrm{B} / \mathrm{W})$ minus the average returns of the two losers $(\mathrm{S} / \mathrm{L}, \mathrm{B} / \mathrm{L})$.

The portfolio construction for TS momentum is similar to CS momentum except for how the stocks are selected, and we use equal-weighted instead of value-weighted returns. ${ }^{4}$ We implement the methodology of Goyal and Jegadeesh (2015) for TS momentum returns. Stocks with positive (negative) returns over the risk-free rate over the past six months (from

\footnotetext{
${ }^{3}$ The results remain robust for equal-weighted returns. We do not report the results to save the space, but are available upon request.

${ }^{4}$ The methodology for TS momentum returns is not suitable for value-weighted returns.
} 
$t$-6 to $t-1)$ are bought (sold). The term, $\left(\sum_{R_{i t-1} \geq 0} R_{i t}\right)$ aggregates the returns of the bought stocks while the term, $\left(\sum_{R_{i t-1<0}} R_{i t}\right)$ sums the returns for the sold stocks. The portfolios are held for six months from $t+1$ to $t+6$. Equation 1 calculates the momentum returns as shown below,

$$
T S\left(M O M_{t)}=\frac{2}{N}\left(\sum_{R_{i t-1} \geq 0} R_{i t}-\sum_{R_{i t-1<0}} R_{i t}\right),\right.
$$

where $T S\left(M O M_{t}\right)$ equals the average monthly momentum returns at time $t$ for TS strategy with a six-month holding period. $\mathrm{N}$ equals the number of stocks while the number two in the numerator allows the comparison between the TS and the CS strategies. Equation 1 corresponds to a zero-cost investment strategy if the same number of stocks are bought and sold. We use excess returns for the holding period because the number of stocks in long and short portfolios might not be equal. Therefore, the strategy involves borrowing at the risk-free rate for the long position and investing the proceeds from the short position at the risk-free rate. $^{5}$

For each holding period month, we apply the methodology of Cooper, Gutierrez and Hameed (2004) to calculate the alphas from the CAPM and Fama-French risk-adjusted returns for both CS and TS momentum returns. The momentum returns ( $\left.\mathrm{MR}_{\mathrm{mt}}\right)$ for month $t$ is regressed on factor i to estimate the loading factor $\left(\beta_{m i}\right)$. The CAPM factor only includes the excess return of the value-weighted market returns over the one-month Treasury bill rate $(M K T)$ while the Fama-French factors add the small-minus-big premium (SMB) and the highbook-to-market-minus-low-book-to-market return premium (HML). The subscript m indexes

${ }^{5}$ The excess returns for the CS momentum strategy are similar to the raw returns because the number of stocks in long and short portfolios is equal. 
a particular holding period where $m=1,2, \ldots 6$. Subsequently, Equation (2) estimates the risk-adjusted momentum returns $\left(M R_{m t}^{a d j}\right)$ after deducting the loading factors.

$$
M R_{m t}^{a d j}=M R_{m t}-\sum_{i} \beta_{i m} f_{i t}
$$

The monthly risk-adjusted CAPM or Fama-French momentum returns are cumulated to form holding-period returns similar to raw momentum returns as described earlier.

\section{Estimating Idiosyncratic Volatility}

Following McLean (2010), we estimate idiosyncratic volatility from the standard deviation of the residuals of Equation (3)

$$
R_{i, t}=\alpha_{i}+\beta_{i 1} R M_{t}+e_{i, t}
$$

where $R_{i, t}$ is the monthly return on stock $i ; R M_{t}$ represents the monthly return of Nikkei225 index while $e_{i, t}$ represents the regression residuals. We estimate Equation (3) for every stock during the formation period using data that spans between $t-36$ and $t-1$ months. Finally, every stock must have at least 30 valid monthly observations.

\section{Empirical Findings}

\section{A. Cross-Sectional and Time-Series Momentum Returns}

Table 2 shows unconditional CS and TS momentum returns. The WML, BH and RB portfolios yield insignificant CS momentum returns of $0.11 \%, 0.13 \%$, and $0.28 \%$ per month, respectively. The results corroborate earlier studies that find relatively weak or no unconditional momentum returns in Japan (Fama and French, 2012, Gong, Liu and Liu, 2015, Griffin, Ji and Martin, 2003, Naranjo and Porter, 2007, Chui, Wei and Titman, 2000, Chui et al., 2010, Asness, 2011, Hanauer, 2014). The alphas of CAPM and Fama-French bear the same conclusion. 
Table 2 shows the TS momentum returns of buy-and-hold $(\mathrm{BH})$ and re-balanced (RB) portfolios. The TS momentum returns exclude the winners-minus-losers approach since it only fits the CS strategy. The BH and RB portfolios generate insignificant TS momentum returns of $0.02 \%$ and $0.03 \%$ per month, respectively. The small and insignificant TS momentum returns are inconsistent with Goyal and Jegadeesh (2015) who find TS momentum returns exceed the CS in U.S. stocks. The alphas of the CAPM and Fama-French agree with the raw momentum returns. Consequently, Japanese markets do not exhibit unconditional momentum returns whether using the CS or TS momentum strategy.

[Table 2 about here]

\section{B. Cross-Sectional Momentum Returns and Market Dynamics}

Table 3 shows the results for CS momentum returns conditioned on market states. ${ }^{6}$ We define market states based on the Nikkei 225 Index returns of lagged 12-month ( $t$-11 to $t)$ and subsequent month $(t+1)$. UP/UP (DN/DN) market state is identified if both lagged and subsequent Nikkei 225 Index returns are positive (negative). The market state is classified as UP/DN (DN/UP) when lagged Nikkei 225 Index returns are positive (negative), and subsequent Nikkei 225 Index returns are negative (positive). ${ }^{7}$

The Japanese market experienced 135 lagged UP markets and 153 lagged DN markets. The market continued in the UP state (UP/UP) for 72 months and transitioned to a DN state (UP/DN) for 63 months. The market continued in the DN state (DN/DN) for 77

\footnotetext{
${ }^{6}$ For conditional momentum returns, we do not use buy-and-hold $(\mathrm{BH})$ portfolios due to the manner in which the subsequent market returns are calculated. For example, BH uses cumulative 6-month market returns $(t+1$ to $t+6)$ to define the subsequent market state. The cumulative returns could have one or more months with negative (positive) market returns that reduce the momentum effect for the $\mathrm{BH}$ portfolios.

${ }^{7}$ The results remain robust if the 36- and 24-month lagged market index returns define the market state. Furthermore, the results remain robust whether we use market returns based on all the stocks or Nikkei-500 Index returns.
} 
months and transitioned to the UP state (DN/UP) for 76 months. The results corroborate those of Hanauer (2014), who finds that the Japanese stock market experienced more market transitions than the U.S. markets.

\section{[Table 3 about here]}

Table 3, Panel A shows WML momentum returns conditioned on market states. WML momentum returns average $1.97 \%(2.20 \%)$ per month when the market continues in the UP (DN) state. In contrast, momentum returns are negative at $-1.38 \%(-2.70 \%)$ per month when the market transitions to the DN (UP) state. ${ }^{8}$ The CAPM and FF alphas bear the same signs as WML momentum returns. Thus, market continuations lead to momentum returns while transitions generate losses. Similar to Hanauer (2014), the results also suggest that Japan does not experience unconditional momentum returns because losses from market transitions eliminate the momentum profits from market continuations.

Table 3, Panel B shows CS momentum returns for RB portfolios conditioned on market states. Similar to WML, momentum returns average $2.07 \%(2.51 \%)$ per month when the market continues in the UP (DN) state. However, market transitions generate losses of $1.62 \%(-2.20 \%)$ per month for UP/DN (DN/UP) state. These results are consistent with those reported by Hanauer (2014).

In sum, the results in Panels A and B show that the Japanese markets earn positive momentum returns in market continuations, which supports the behavioural theory of Daniel et al. (1998).

${ }^{8}$ We find momentum crashes when market transitions to the UP state because loser's portfolio earns greater returns than the winner's portfolio when the market rebounds. Daniel and Moskowitz (2016) argue momentum crashes are driven by the option-like behaviour of the loser's portfolio. Grobys (2016) also finds support for an option like behaviour in the European Monetary Union but only based on the intermediate past performance momentum strategy of Novy-Marx (2012). 


\section{Time-Series Momentum Returns and Market Dynamics}

For the TS strategies, we follow the same procedure as in the CS strategies using excess returns except that the stock's own performance determine the portfolio selection (Refer to Equation 1). Table 4 shows TS momentum returns conditioned on both the past and subsequent market states. TS momentum returns are $2.24 \%(3.43 \%)$ per month when the market continues in the UP (DN) state. As markets transition to another state, momentum returns generate losses that are $-2.10 \%(-3.93 \%)$ per month when the market transitions to DN (UP) state. The CAPM and FF alphas bear the same signs as the momentum returns and losses.

\section{[Table 4 about here]}

We find higher number of DN markets (153 months) than UP markets (135 months) which could explain the small and insignificant unconditional TS momentum returns in Japan. Goyal and Jegadeesh (2015) argue that more UP than DN markets cause TS momentum returns to exceed CS momentum returns due to the net long position and its corresponding risk premium. However, we find that the net short position can also generate momentum returns when markets continue in the DN state. In fact, a net long (short) position generates momentum returns when the market continues in UP (DN) state. Therefore, the absence of conditional TS momentum returns in Japan results from the offsetting momentum losses when the market transitions against the momentum profits when it continues in the same state. Market timing becomes salient in the data and supports the net long (short) position of the TS strategy following UP (DN) markets. For example, the TS portfolios buy (sell) on average 2129 (1167) stocks per month following UP markets and 945 (2086) stocks following DN markets. 
In Table 4, we include all the stocks with excess positive (negative) formation period returns in the TS strategy and find comparatively higher TS momentum returns compared to the CS strategy that includes top (bottom) decile of formation period returns. Therefore, we expect even higher conditional TS momentum returns if we impose a cut-off point to buy (sell) the top (worst) performers with past excess positive (negative) returns. Based on the model of Daniel et al. (1998), investor overconfidence will be even greater if the formation period returns on the stocks they bought (sold) are extremely positive (negative). The \pm 1 standard deviation from the mean defines the cut-off points to buy and sell stocks. ${ }^{9}$

Table 5 reports the TS momentum returns with the \pm 1 cut-off points. The number of stocks in the winner (loser) portfolio falls to 595 (155) following the UP markets while the number of stocks drops to 151 (514) following the DN markets. The TS strategy earns greater momentum returns of $4.31 \%$ (3.99\%) per month for UP (DN) market continuations. In contrast market transitions lead to losses of $-4.16 \%(-5.58 \%)$ per month when the market transitions to the DN (UP) state. In sum, the results in Table 5 indicate that markets continuing in the same state generate greater momentum returns after imposing the cut-off point, which supports Daniel et al. (1998).

\section{[Table 5 about here]}

\section{Momentum Returns and Idiosyncratic Volatility}

Idiosyncratic volatility (IV) serves as a proxy for firm-specific information. Accordingly, a relation between momentum returns and IV would support the investor

\footnotetext{
${ }^{9}$ The sample includes approximately $20 \%$ (32\%) of the stocks with a cut-off point of $\pm 1.28( \pm 1)$ standard deviation from the mean. Setting the standard deviation to \pm 1 from the mean ensures the winner and loser portfolios have stocks. Higher cut-off points cause some loser and winner portfolios to hold zero stocks for few months.
} 
underreaction models of Barberis et al. (1998) and Hong and Stein (1999) and also the overconfidence and self-attribution model of Daniel et al. (1998). We test whether IV influences momentum returns using rebalanced portfolios. ${ }^{10}$ Following the literature, (e.g. Arena et al., 2008, McLean, 2010), at the beginning of each month $t+1$, we independently sort the stocks into $10 \mathrm{CS}$ (two TS) portfolios and three IV portfolios. ${ }^{11}$ These portfolios are held for six months ( $t+1$ to $t+6)$. At the end of each holding period, the momentum returns for each IV (low, medium, high) portfolio equal the winner minus loser portfolio.

Table 6, Panel A reports CS momentum returns sorted on IV while Panel B shows TS momentum returns sorted by IV. All IV terciles for both CS and TS indicate small and statistically insignificant momentum returns. Furthermore, the momentum returns between the high IV portfolios and low IV portfolios are not statistically different from zero. Hence, the results resemble the unconditional momentum returns in Table 2.

\section{[Table 6 about here]}

Our results in Table 6 show that the positive relation between momentum returns and IV documented by Arena et al. (2008) in the U.S. is absent in Japan. These results are inconsistent with the prediction of a positive relation between momentum returns and IV based on both underreaction and the overconfidence and self-attribution theories of momentum. However, our results are consistent with the views of McLean (2010) based on U.S. markets who suggests that IV is not a limit to the arbitrage of momentum returns. Instead, McLean (2010) suggests that momentum is a smaller mispricing; therefore,

\footnotetext{
${ }^{10}$ The results remain robust whether we use buy-and-hold or WML portfolios. The results stay the same if we use two or five IV portfolios, and three or five momentum portfolios.

${ }^{11}$ McLean (2010) sorts the stocks into 5 IV and 5 momentum portfolios; whereas, Arena et al. (2008) sort into $3 \mathrm{IV}$ and 5 momentum portfolios. Our results remain unchanged if we sort into 5 IV and 5 momentum portfolios.
} 
transactions costs are the most likely limit to the arbitrage of momentum returns. McLean's (2010) argument is in line with Lesmond, Schill and Zhou (2004) who report a positive relation between momentum returns and transaction costs in the U.S. markets, and show that momentum returns do not exceed transaction costs. We find that unconditional momentum returns in Japan are almost zero; whereas conditional momentum returns are significant and might persist because of transaction costs and bid-ask spread in Japan. ${ }^{12}$

The results in Table 6 show the absence of momentum returns in Japan when sorted on IV. However, we find momentum returns in the previous sections when we condition it on market dynamics. Therefore, we test whether a positive relation exists between momentum returns and IV especially when the market continues in the same state. Panel A of Table 7 reports IV-sorted CS momentum returns of rebalanced portfolios conditioned on market dynamics. Similar to the results shown in Panel A of Table 3, large and significant CS momentum profits occur when the market continues in the same state and generates large and significant momentum losses in market transitions. The Panel B of Table 7 shows large and significant TS momentum profits when the market continues in the same state and large and significant momentum losses when the market transitions to another state. However, the results in Table 7 still show no relation between momentum returns and IV since the difference in momentum returns between the high and low IV portfolios is insignificant.

\section{[Table 7 about here]}

In sum, we do not find any relation between momentum returns and IV in Japan even when we condition CS and TS momentum returns on market dynamics. However, we still

\footnotetext{
12 The transaction costs in Japan vary by transaction size, starting at $1.15 \%$ per trade for trades under 1 million yen and declining as the trading value increases, with the rate being $0.075 \%$ per trade for trades exceeding 1 billion yen (e.g. Liu and Zhu, 2009).
} 
find higher and significant momentum return when the market continues in the same state even after sorting stocks on IV. Therefore, our results support Daniel et al. (1998) model that predicts higher momentum returns in market continuations. In contrast, we do not find support for for the underreaction models of Barberis et al. (1998) and Hong and Stein (1999).

\section{Robustness Tests}

\section{A. Momentum Returns, Market Dynamics and the 2008 Financial Crisis}

In this section, we examine the robustness of our main findings before the 2008 financial crisis (1990-2007) and during and after the crisis (2008-2014). ${ }^{13}$ We follow classification for CS momentum returns, TS momentum returns, UP/UP, UP/DN, DN/UP and DN/DN market states as in Sections III.B and III.C.

\section{[Table 8 about here]}

Table 8 reports momentum returns of both CS and TS strategies conditioned on market dynamics. Panel A reports momentum returns before the 2008 Financial Crisis and Panel B during and after the 2008 Financial Crisis. We find large and significant CS and TS momentum returns before the 2008 financial crisis. For example, CS momentum returns are $2.36 \%(2.70 \%)$ per month when the market continues in UP (DN) state. The TS momentum returns are $1.91 \%(3.39 \%)$ per month when the market continues in UP (DN) state. We find similar trends in Panel B for both CS and TS momentum returns. Our results suggest that momentum trading strategies are profitable only when the market continues in the same state. Therefore, momentum trading strategies could generate significant profits during economic expansions (recessions) where stocks on average earn positive (negative) returns. In contrast, momentum strategies incur losses in market transitions, e.g., from expansion to recession.

\footnotetext{
${ }^{13}$ We thank the referee for suggesting this test.
} 


\section{B. Momentum Returns, Market Dynamics and Alternative Holding Periods}

Recall from Section III that we used the conventional 6-month formation and 6month holding periods for both CS and TS strategies, consistent with the literature (Asem and Tian, 2010, Cooper et al., 2004, McLean, 2010, Jegadeesh and Titman, 2001). In this section, we examine whether our main finding that momentum returns are large and significant when the market continues in the same state, survive alternative holding periods. ${ }^{14} \mathrm{We}$ follow similar classification for CS momentum returns, TS momentum returns, UP/UP, UP/DN, DN/UP and DN/DN market states as in Sections III.B and III.C.

\section{[Table 9 about here]}

Table 9 reports the CS and TS momentum returns for $k$-holding $(k=3,9$ and 12$)$ months. ${ }^{15}$ Panel A reports CS momentum returns. We find large and significant momentum returns when the market continues in the same state. For example, momentum returns are $1.63 \%(2.68 \%)$ per month, $2.04 \%(2.21 \%)$ per month and $1.45 \%(1.60 \%)$ per month for 3-, 9and 12-month holding periods, respectively when the market state is UP/UP (DN/DN). Panel B reports TS momentum returns. Similar to the results in Panel A, we find large and significant TS momentum returns when the market continues in the same state. In sum, our main findings that momentum returns are large and significant when the market continues in the same state hold for alternative periods.

\section{Conclusion}

We find that momentum returns are conditioned by market states irrespective of whether we employ cross-sectional (CS) or time-series (TS) momentum strategies.

\footnotetext{
${ }^{14} \mathrm{We}$ thank the referee for suggesting this test.

${ }^{15} \mathrm{We}$ also examine the robustness of our main findings for alternative formation periods (3-, 9- and 12month) and our results remain similar. We do not report those results to save the space but are available upon request.
} 
Specifically, we find momentum profits for markets continuing in the same state while we document momentum losses when markets transition to a different state. This is consistent with the overconfidence and self-attribution model of Daniel et al. but not with the underreaction model of Hong and Stein.

We find that the TS conditional momentum returns exceed the conditional CS momentum returns although the TS strategy uses only two portfolios compared with the CS which utilizes ten. The returns of the TS strategy exceeds CS because the former takes a net long (short) position following UP (DN) markets which generate greater TS returns, consistent with the model of Daniel et al. (1998) since a subsequent increase (decrease) after a buy (sell) trade further enhances investor overconfidence. If we exclude stocks that lie between \pm 1 standard deviation around the mean, TS momentum profits become even larger. The cut-off point excludes stocks with mediocre returns and further supports Daniel et al. (1998).

Finally, we find no relation between idiosyncratic volatility and momentum returns. Though this is not supportive of any of the three behavioural models, it implies that idiosyncratic volatility is not a significant limit to arbitrage in the Japanese market.

Our results imply that money managers could earn returns using the momentum strategy when they expect the market trend to continue in the same direction, e.g., UP/UP or DN/DN. However, this strategy turns to losses if the market transitions; therefore, it is quite risky. 


\section{References}

Arena, M. P., K. S. Haggard and X. S. Yan (2008), 'Price momentum and idiosyncratic volatility', The Financial Review, 43, 159-90.

Asem, E. and G. Y. Tian (2010), 'Market dynamics and momentum profits', Journal of Financial and Quantitative Analysis, 45, 1549-62.

Asness, C. (2011), 'Momentum in Japan: The exception that proves the rule', The Journal of Portfolio Management, 37, 67-75.

Barberis, N., A. Shleifer and R. Vishny (1998), 'A model of investor sentiment', Journal of Financial Economics, 49, 307-43.

Carhart, M. M. (1997), 'On persistence in mutual fund performance', The Journal of Finance, $52,57-82$.

Cheema, M. A., G. V. Nartea and Y. Man (2017), 'Cross-Sectional and Time Series Momentum Returns and Market States', International Review of Finance, n/a-n/a.

Chui, A. C., S. Titman and K. J. Wei (2010), 'Individualism and momentum around the world', The Journal of Finance, 65, 361-92.

Chui, A. C. W., K. C. Wei and S. Titman (2000), 'Momentum, legal systems and ownership structure: An analysis of Asian stock markets', University of Texas at Austin working paper.

Cooper, M. J., R. C. Gutierrez and A. Hameed (2004), 'Market states and momentum', The Journal of Finance, 59, 1345-65.

Daniel, K. and T. J. Moskowitz (2016), 'Momentum crashes', Journal of Financial Economics, $122,221-47$.

Daniel, K. D., D. Hirshleifer and A. Subrahmanyam (1998), 'Investor psychology and security market under- and overreactions', The Journal of Finance, 53, 1839-85.

Fama, E. F. and K. R. French (1996), 'Multifactor explanations of asset pricing anomalies', The Journal of Finance, 51, 55-84.

Fama, E. F. and K. R. French (2012), 'Size, value, and momentum in international stock returns', Journal of Financial Economics, 105, 457-72.

Gong, Q., M. Liu and Q. Liu (2015), 'Momentum is really short-term momentum', Journal of Banking \& Finance, 50, 169-82.

Goyal, A. and N. Jegadeesh (2015), 'Cross-Sectional and Time-Series Tests of Return Predictability: What is the Difference?', Available at SSRN 2610288. 
Griffin, J. M., X. Ji and J. S. Martin (2003), 'Momentum investing and business cycle risk: Evidence from pole to pole', Journal of Finance, 2515-47.

Griffin, J. M., P. J. Kelly and F. Nardari (2010), 'Do Market Efficiency Measures Yield Correct Inferences? A Comparison of Developed and Emerging Markets', The Review of Financial Studies, 3225-77.

Grobys, K. (2016), 'Another look at momentum crashes: momentum in the European Monetary Union', Applied Economics, 48, 1759-66.

Hanauer, M. (2014), 'Is Japan Different? Evidence on Momentum and Market Dynamics', International Review of Finance, 14, 141-60.

Hong, H. and J. C. Stein (1999), 'A unified theory of underreaction, momentum trading, and overreaction in asset markets', The Journal of Finance, 54, 2143-84.

Ince, O. S. and R. B. Porter (2006), 'Individual equity return data from Thomson Datastream: Handle with care!', Journal of Financial Research, 29, 463-79.

Jegadeesh, N. and S. Titman (1993), 'Returns to buying winners and selling losers: Implications for stock market efficiency', The Journal of Finance, 48, 65-91.

Jegadeesh, N. and S. Titman (2001), 'Profitability of Momentum Strategies: An Evaluation of Alternative Explanations', The Journal of Finance, 56, 699-720.

Lesmond, D. A., M. J. Schill and C. Zhou (2004), 'The illusory nature of momentum profits', Journal of Financial Economics, 71, 349-80.

Liu, S. and Z. Zhu (2009), 'Transaction costs and price volatility: new evidence from the Tokyo Stock Exchange', Journal of Financial Services Research, 36, 65-83.

Mclean, R. D. (2010), 'Idiosyncratic risk, long-term reversal, and momentum', Journal of Financial and Quantitative Analysis, 45, 883-906.

Moskowitz, T. J., Y. H. Ooi and L. H. Pedersen (2012), 'Time series momentum', Journal of Financial Economics, 104, 228-50.

Naranjo, A. and B. Porter (2007), 'Including emerging markets in international momentum investment strategies', Emerging Markets Review, 8, 147-66.

Novy-Marx, R. (2012), 'Is momentum really momentum?', Journal of Financial Economics, $103,429-53$.

Schmidt, P. S., U. Von Arx, A. Schrimpf, A. F. Wagner and A. Ziegler (2014), 'On the construction of common size, value and momentum factors in international stock markets: A guide with applications', Swiss Finance Institute Research Paper. 
Shleifer, A. and R. W. Vishny (1997), 'The limits of arbitrage', The Journal of Finance, 52, 3555. 


\section{Table 1: Descriptive Statistics}

Panel A reports summary statistics of the Nikkei225 Index monthly returns (Nikkei225), market returns (RM), the risk-free rate (RF), small-minus-big size factor (SMB) and high-minus-low book-to-market factor (HML) while Panel B shows the correlations. The Fama-French Library for Japan provides the RM, RF, SMB, and HML. Datastream International furnishes the Nikkei 225 Index return. The sample period ranges from January 1990 to December 2014.

\begin{tabular}{lccccc}
\hline \multicolumn{5}{c}{ Panel A: Descriptive Statics } \\
\hline Variable & Mean & Std Dev & Median & Maximum & Minimum \\
\hline Nikkei225 & -0.008 & 6.236 & -0.02 & 20.066 & -23.827 \\
RM & 0.208 & 5.975 & 0.6 & 25.59 & -17.43 \\
RF & 0.244 & 0.185 & 22.64 & 0.68 & 0.00 \\
SMB & -0.028 & 3.299 & -0.14 & 12.99 & -11.15 \\
HML & 0.419 & 2.778 & 2.59 & 10.08 & -13.82 \\
\hline \multicolumn{7}{c}{ Panel B: Correlations } & & HML \\
\hline Variable & RM & RF & SMB & \\
\hline Nikkei225 & 1 & & & 1 \\
RM & 0.81 & 1 & 1 & 0.07 & \\
RF & -0.11 & -0.08 & -0.15 & & \\
SMB & 0.01 & 0.12 & 0.02 & & \\
HML & -0.17 & -0.17 & & & \\
\hline
\end{tabular}




\section{Table 2: Unconditional cross-sectional and time-series momentum returns}

The table presents momentum returns for cross-sectional winners-minus-losers (CS-WML), re-balanced crosssectional (RB-CS), buy-and-hold cross-sectional (BH-CS), re-balanced time-series (RB-TS), and buy-and-hold time-series (BH-TS). For CS-WML, at the beginning of each month $t+1$, all stocks are ranked on their returns between months $t-11$ and $t-1$ and sorted into three groups: losers (L) as the bottom $30 \%$, medium (M) as the middle $40 \%$ and the winners $(\mathrm{W})$ as top $30 \%$. Stocks are also divided into two groups based on market capitalization at month $t$ : bottom $10 \%$ as the small (S) and the top $90 \%$ as big (B). Consequently, all stocks are sorted into 6 portfolios: S/L, S/M, S/B, B/L, B/M and B/W. The value-weighted returns of these portfolios are calculated for month $t+1$, and month $t$ is skipped to mitigate bid-ask bounce effect. WML equal the difference between the average monthly returns of the two winners $(\mathrm{S} / \mathrm{W}$ and $\mathrm{B} / \mathrm{W})$ and the average return of the two losers $(\mathrm{S} / \mathrm{L}$ and $\mathrm{B} / \mathrm{L})$. For RB-CS and BH-CS, at the beginning of each month $t+1$, all stocks are sorted into deciles based on their lagged 6-month ( $t$-6 to $t$-1) returns, and stocks with highest (lowest) 6-month lagged returns are bought (sold). These portfolios are held for 6 months $(t+1$ to $t+6)$. Both re-balanced and buy-and-hold portfolios use the methodology of Jegadeesh and Titman (1993) to calculate momentum returns. For time series RB-TS and BH-TS momentum returns, the same procedures are followed except that stocks are selected on their own performance. Stock with a positive (negative) risk-free excess return is included in the winner (loser) portfolio (see equation 1). Both re-balanced and buy-and-hold portfolios use the methodology of Jegadeesh and Titman (1993) to calculate RB-TS and BH-TS momentum returns. The table shows the average monthly returns of loser and winner portfolios, momentum returns, and alphas for the CAPM and Fama-French with $t$-statistics in parentheses. The $t$ statistics are adjusted for buy-and-hold portfolios using Newey-West while the simple $t$-statistics are shown for the other portfolios. The sample period ranges from January 1990 to December 2014.

\begin{tabular}{lccccc}
\hline Momentum Returns & CS-WML & BH-CS & RB-CS & BH-TS & RB-TS \\
\hline Loser & 0.27 & 0.21 & 0.16 & 0.18 & 0.19 \\
& $(0.66)$ & $(0.50)$ & $(0.33)$ & $(0.39)$ & $(0.42)$ \\
Winner & 0.38 & 0.34 & 0.44 & 0.20 & 0.22 \\
& $(1.16)$ & $(0.86)$ & $(1.05)$ & $(0.59)$ & $(0.61)$ \\
Momentum Returns & 0.11 & 0.13 & 0.28 & 0.02 & 0.03 \\
& $(0.39)$ & $(0.39)$ & $(0.72)$ & $(0.06)$ & $(0.06)$ \\
CAPM Alpha & 0.12 & 0.12 & 0.29 & 0.03 & 0.04 \\
& $(0.40)$ & $(0.36)$ & $(0.73)$ & $(0.07)$ & $(0.10)$ \\
Fama-French Alpha & 0.26 & 0.13 & 0.55 & 0.04 & 0.02 \\
& $(0.92)$ & $(0.39)$ & $(1.47)$ & $(0.11)$ & $(0.04)$ \\
\hline
\end{tabular}




\section{Table 3: Cross-sectional momentum returns and market dynamics}

The panel A of this table presents Winners minus Losers (WML) momentum returns while Panel B shows momentum returns $(\mathrm{RB})$ based on re-balanced portfolios. For WML, all stocks are ranked on their returns at the end of each month $t$ from month $t-11$ to $t-1$ and divided into three groups: losers (L) as the bottom $30 \%$, medium (M) as $40 \%$ and winners as top $30 \%$. Stocks are further sorted into two groups based on market capitalization of month $t$, bottom $10 \%$ as small (S) and top $90 \%$ big (B). Thus, all stocks are sorted into six portfolios: S/L, S/M, $\mathrm{S} / \mathrm{B}, \mathrm{B} / \mathrm{L}, \mathrm{B} / \mathrm{M}$ and $\mathrm{B} / \mathrm{W}$. The value-weighted returns of these portfolios are calculated for month $t+1$, and month $t$ is skipped to mitigate bid-ask bounce effect. WML equals the average monthly returns of the two winners portfolios (S/W and B/W) minus the average of the two losers ( $\mathrm{S} / \mathrm{L}$ and B/L) portfolios. As in Jegadeesh and Titman (1993), we rebalance the portfolios monthly for RB momentum returns. For RB momentum returns, all stocks are sorted into deciles at the beginning of each month $t+1$ based on their lagged 6-month ( $t$ - 6 to $t-1)$ returns, and stocks with highest (lowest) 6-month lagged returns are bought (shorted). These portfolios are held for 6 months $(t+1$ to $t+6)$. At the beginning of month $t+1$, positive (negative) Nikkei225 Index returns over past $12(t$ 11 to $t$ ) months and Nikkei225 Index subsequent returns over the holding period $t+1$ are used to define UP/UP, UP/DN, DN/UP and DN/DN market states. If lagged and subsequent market returns are positive (negative), the market state is defined as UP/UP (DN/DN). If lagged market returns are positive (negative), and subsequent market returns are negative (positive), then the market state is defined as UP/DN (DN/UP). The table reports the average monthly returns of the loser and winner portfolios, momentum returns, and CAPM and Fama-French Alphas in the table with $t$-statistics in the parentheses. The sample period ranges from January 1990 to December 2014.

\begin{tabular}{|c|c|c|c|c|}
\hline & UP/UP & UP/DN & DN/UP & DN/DN \\
\hline$N$ & 72 & 63 & 76 & 77 \\
\hline \multirow[t]{2}{*}{ P1 } & 2.94 & -2.30 & 6.30 & -5.99 \\
\hline & (6.57) & $(-4.84)$ & (6.91) & $(-11.83)$ \\
\hline \multirow[t]{2}{*}{ P10 } & 4.91 & -3.68 & 3.60 & -3.79 \\
\hline & (9.80) & $(-7.00)$ & (8.43) & $(-9.25)$ \\
\hline \multirow[t]{2}{*}{ P10-P1 } & 1.97 & -1.38 & -2.70 & 2.20 \\
\hline & $(4.10)$ & $(-2.96)$ & $(-3.64)$ & $(5.91)$ \\
\hline \multirow[t]{2}{*}{ CAPM ALPHA } & 2.40 & -1.74 & -2.17 & 1.58 \\
\hline & $(4.77)$ & $(-3.52)$ & $(-3.08)$ & $(4.30)$ \\
\hline \multirow[t]{2}{*}{ Fama-French (FF) ALPHA } & 2.46 & -1.53 & -2.13 & 1.84 \\
\hline & $(5.32)$ & $(-3.04)$ & $(-3.11)$ & $(5.20)$ \\
\hline \multicolumn{5}{|c|}{ Panel B: RB momentum returns following lagged 12-month and subsequent $(t+1)$ market returns } \\
\hline & UP/UP & UP/DN & DN/UP & $\mathrm{DN} / \mathrm{DN}$ \\
\hline$N$ & 72 & 63 & 76 & 77 \\
\hline \multirow[t]{2}{*}{$\mathrm{P} 1$} & 3.44 & -2.75 & 6.44 & -6.69 \\
\hline & (5.88) & $(-4.46)$ & $(6.24)$ & $(-11.27)$ \\
\hline \multirow[t]{2}{*}{$\mathrm{P} 10$} & 5.51 & -4.37 & 4.25 & -4.19 \\
\hline & (7.26) & $(-5.91)$ & (8.36) & $(-8.02)$ \\
\hline \multirow[t]{2}{*}{ P10-P1 } & 2.07 & -1.62 & -2.20 & 2.51 \\
\hline & (2.49) & $(-2.48)$ & $(-2.36)$ & $(4.60)$ \\
\hline \multirow[t]{2}{*}{ CAPM ALPHA } & 2.50 & -1.98 & -1.67 & 1.89 \\
\hline & (2.95) & $(-2.94)$ & $(-1.86)$ & (3.46) \\
\hline \multirow[t]{2}{*}{ Fama-French (FF) ALPHA } & 2.63 & -1.62 & -1.59 & 2.38 \\
\hline & (3.55) & $(-2.35)$ & $(-1.85)$ & (4.34) \\
\hline
\end{tabular}




\section{Table 4: Time-series momentum returns and market dynamics}

The table presents time-series momentum returns conditioned on market dynamics. At the beginning of each month $t+1$, the cumulative returns in excess of the risk-free are calculated (see equation 1 ). Stocks with positive (negative) 6-month lagged returns are bought (sold). These portfolios are held for 6 months $(t+1$ to $t+6)$, and month $t$ is skipped to mitigate the bid-ask bounce effect. At the beginning of month $t+1$, positive (negative) Nikkei225 Index returns over past $12(t-11$ to $t)$ months and Nikkei225 Index subsequent returns over the holding period $t+1$ are used to define UP/UP, UP/DN, DN/UP and DN/DN market states. The UP/UP (DN/DN) market state has positive (negative) lagged and subsequent market returns. The UP/DN (DN/UP) transition state has a positive (negative) lagged market returns and a negative (positive) subsequent market returns. As in Jegadeesh and Titman (1993), we use the rebalanced portfolios. The table reports the average monthly returns of the loser and winner portfolios, momentum returns, and CAPM and Fama-French Alphas with $t$-statistics in the parentheses. The sample period ranges from January 1990 to December 2014.

\begin{tabular}{lcccr}
\hline \multicolumn{4}{c}{ TS momentum returns following lagged 12-month and contemporaneous $(t+1)$ market returns } \\
\hline$N$ & UP/UP & UP/DN & DN/UP & DN/DN \\
\hline LOSER & 72 & 63 & 76 & 77 \\
& 2.39 & -1.57 & 6.17 & -6.25 \\
WINNER & $(5.45)$ & $(-3.12)$ & $(5.76)$ & $(-8.47)$ \\
& 4.62 & -3.67 & 2.24 & -2.82 \\
MOMENTUM RETURNS & $(6.49)$ & $(-4.81)$ & $(6.06)$ & $(-8.04)$ \\
& 2.24 & -2.10 & -3.93 & 3.43 \\
CAPM ALPHA & $(3.86)$ & $(-3.34)$ & $(-4.34)$ & $(5.48)$ \\
& 3.07 & -2.80 & -2.90 & 2.23 \\
Fama-French (FF) ALPHA & $(4.92)$ & $(-4.05)$ & $(-3.49)$ & $(3.74)$ \\
& 2.94 & -2.64 & -2.95 & 2.19 \\
& $(4.38)$ & $(-3.6)$ & $(-3.86)$ & $(4.05)$ \\
\hline
\end{tabular}




\section{Table 5: Time-series momentum returns and market dynamics with cut-off points}

This table presents time-series momentum returns with cut-off points conditioned on market dynamics. At the beginning of each month $t+1$, the stocks with cumulative returns ( $t-6$ to $t$-1) above (below) the one standard deviation from mean are bought (sold). These portfolios are held for 6 months ( $t+1$ to $t+6)$, and month $t$ is skipped to mitigate the bid-ask bounce effect. At the beginning of month $t+1$, positive (negative) Nikkei225 Index returns over past 12 ( $t$-11 to $t$ ) months and Nikkei225 Index subsequent returns over the holding period $t+1$ are used to define UP/UP, UP/DN, DN/UP and DN/DN market states. The UP/UP (DN/DN) market state has positive (negative) lagged and subsequent market returns. The UP/DN (DN/UP) transition state has a positive (negative) lagged market returns and a negative (positive) subsequent market returns. As in Jegadeesh and Titman (1993), we use the rebalanced portfolios. The table reports the average monthly returns of the loser and winner portfolios, momentum returns, and CAPM and Fama-French Alphas with $t$-statistics in the parentheses. The sample period ranges from January 1990 to December 2014.

\begin{tabular}{|c|c|c|c|c|}
\hline \multicolumn{5}{|c|}{ TS momentum returns following lagged 12-month and subsequent $(t+1)$ market returns } \\
\hline & UP/UP & UP/DN & DN/UP & $\mathrm{DN} / \mathrm{DN}$ \\
\hline$N$ & 72 & 63 & 76 & 77 \\
\hline \multirow[t]{2}{*}{ LOSER } & 2.10 & -1.55 & 8.36 & -7.86 \\
\hline & (3.58) & $(-2.07)$ & (5.65) & $(-7.84)$ \\
\hline \multirow[t]{2}{*}{ WINNER } & 6.40 & -5.71 & 2.78 & -3.87 \\
\hline & (6.08) & $(-5.31)$ & (5.35) & $(-7.55)$ \\
\hline \multirow[t]{2}{*}{ MOMENTUM RETURNS } & 4.31 & -4.16 & -5.58 & 3.99 \\
\hline & $(4.28)$ & $(-4.03)$ & $(-4.00)$ & (3.98) \\
\hline \multirow[t]{2}{*}{ CAPM ALPHA } & 5.17 & -4.89 & -4.52 & 2.75 \\
\hline & $(4.93)$ & $(-4.46)$ & $(-3.43)$ & (2.84) \\
\hline \multirow[t]{2}{*}{ Fama-French (FF) ALPHA } & 5.01 & -4.72 & -4.59 & 2.68 \\
\hline & $(4.53)$ & $(-4.14)$ & $(-3.65)$ & (2.94) \\
\hline
\end{tabular}




\section{Table 6: Momentum returns sorted on IV}

The table reports the cross-sectional (CS) and time-series (TS) average monthly momentum returns and CAPM and Fama-French three-factor alphas that are cross-sorted into IV terciles. Panel A reports CS momentum returns while Panel B reports TS momentum returns. Firm IV is the standard deviation of the residuals over the past 36 months (see section 2.C for a detailed description). Stocks are sorted on past returns and IV independently. For CS momentum returns, at the beginning of each month $t+1$, stocks are sorted into deciles based on their lagged 6month ( $t-6$ to $t$-1) returns, and stocks with highest (lowest) 6-month lagged returns are bought (sold). These portfolios are held for 6 months $(t+1$ to $t+6)$. For TS momentum returns, the same procedures are followed except that stocks are selected based on their own performance. Stock with a positive (negative) risk-free excess return is included in the winner (loser) portfolio (see section 2.B for a detailed description). As in Jegadeesh and Titman (1993), we use the rebalanced portfolios. The table reports the average monthly returns of the loser and winner portfolios, momentum returns, and CAPM and Fama-French Alphas with $t$-statistics in the parentheses. The sample period ranges from January 1990 to December 2014.

\begin{tabular}{|c|c|c|c|c|c|}
\hline \multicolumn{6}{|c|}{ Panel A: Cross-sectional momentum returns } \\
\hline IV & $\mathrm{L}$ & W & MOM & CAPM & FF \\
\hline Low & $\begin{array}{c}0.54 \\
(1.86)\end{array}$ & $\begin{array}{c}0.51 \\
(1.96)\end{array}$ & $\begin{array}{c}-0.03 \\
(-0.31)\end{array}$ & $\begin{array}{c}-0.03 \\
(-0.33)\end{array}$ & $\begin{array}{c}0.00 \\
(0.02)\end{array}$ \\
\hline Med & $\begin{array}{c}0.63 \\
(1.66)\end{array}$ & $\begin{array}{c}0.53 \\
(1.55)\end{array}$ & $\begin{array}{c}-0.10 \\
(-0.84)\end{array}$ & $\begin{array}{c}-0.10 \\
(-0.85)\end{array}$ & $\begin{array}{c}-0.06 \\
(-0.52)\end{array}$ \\
\hline High & $\begin{array}{c}0.45 \\
(0.89)\end{array}$ & $\begin{array}{c}0.33 \\
(0.72)\end{array}$ & $\begin{array}{c}-0.12 \\
(-0.78)\end{array}$ & $\begin{array}{c}-0.12 \\
(-0.78)\end{array}$ & $\begin{array}{l}-0.06 \\
(-0.4)\end{array}$ \\
\hline High-Low & $\begin{array}{c}-0.10 \\
(-0.37)\end{array}$ & $\begin{array}{c}-0.18 \\
(-0.69)\end{array}$ & $\begin{array}{c}-0.08 \\
(-0.84)\end{array}$ & $\begin{array}{c}-0.08 \\
(-0.83)\end{array}$ & $\begin{array}{c}-0.06 \\
(-0.62)\end{array}$ \\
\hline \multicolumn{6}{|c|}{ Panel B: Time-series momentum returns } \\
\hline IV & $\mathrm{L}$ & $\mathrm{W}$ & MOM & CAPM & $\mathrm{FF}$ \\
\hline Low & $\begin{array}{c}0.17 \\
(0.54)\end{array}$ & $\begin{array}{c}0.36 \\
(1.27)\end{array}$ & $\begin{array}{c}0.19 \\
(0.63)\end{array}$ & $\begin{array}{c}0.19 \\
(0.63)\end{array}$ & $\begin{array}{c}0.19 \\
(0.63)\end{array}$ \\
\hline Med & $\begin{array}{c}0.42 \\
(0.94)\end{array}$ & $\begin{array}{c}0.30 \\
(0.81)\end{array}$ & $\begin{array}{c}-0.12 \\
(-0.28)\end{array}$ & $\begin{array}{c}-0.12 \\
(-0.29)\end{array}$ & $\begin{array}{c}-0.13 \\
(-0.31)\end{array}$ \\
\hline High & $\begin{array}{c}0.24 \\
(0.41)\end{array}$ & $\begin{array}{c}0.17 \\
(0.33)\end{array}$ & $\begin{array}{c}-0.08 \\
(-0.15)\end{array}$ & $\begin{array}{c}-0.08 \\
(-0.16)\end{array}$ & $\begin{array}{c}-0.13 \\
(-0.25)\end{array}$ \\
\hline High-Low & $\begin{array}{c}0.07 \\
(0.21)\end{array}$ & $\begin{array}{c}-0.20 \\
(-0.67)\end{array}$ & $\begin{array}{c}-0.27 \\
(-0.88)\end{array}$ & $\begin{array}{c}-0.27 \\
(-0.89)\end{array}$ & $\begin{array}{c}-0.32 \\
(-1.05)\end{array}$ \\
\hline
\end{tabular}




\section{Table 7: Momentum returns sorted on IV and market dynamics}

The table presents the cross-sectional (CS) and time-series (TS) average monthly momentum returns that are cross-sorted into IV terciles and conditioned on market dynamics. Panel A reports CS momentum returns while Panel B reports TS momentum returns. At the beginning of month $t+1$, we use the Nikkei225 Index returns over past $12(t-11$ to $t)$ months and Nikkei225 Index subsequent returns over the holding period $t+1$ to define the market states. If lagged and subsequent market returns are positive (negative), the market state is defined as UP/UP (DN/DN). If lagged market returns are positive (negative), and subsequent market returns are negative (positive), then the market state is defined as UP/DN (DN/UP). Firm IV is the standard deviation of the residuals over the past 36 months (see section 2.C for a detailed description). Stocks are sorted on past returns and IV independently. For CS momentum returns, at the beginning of each month $t+1$, all stocks are sorted into deciles based on their lagged 6-month ( $t$-6 to $t$-1) returns, and stocks with highest (lowest) 6-month lagged returns are bought (sold). These portfolios are held for 6 months $(t+1$ to $t+6)$. For TS momentum returns, the same procedures are followed except that stocks are selected on their own performance. Stock with a positive (negative) risk-free excess return is included in the winner (loser) portfolio (see section 2.B for a detailed description). As in Jegadeesh and Titman (1993), we use the rebalanced portfolios. The table reports the average monthly returns of the loser and winner portfolios, momentum returns, and CAPM and Fama-French Alphas with $t$-statistics in the parentheses. The sample period ranges from January 1990 to December 2014.

\begin{tabular}{lcccc}
\hline \multicolumn{5}{c}{ Panel A: Cross-sectional momentum returns sorted on IV and conditioned on market dynamics } \\
\hline Market & Low IV & Med IV & High IV & High-Low IV \\
\hline \multirow{2}{*}{ UP/UP } & 0.48 & 0.43 & 0.48 & -0.01 \\
& $(3.67)$ & $(2.46)$ & $(1.89)$ & $(-0.02)$ \\
\multirow{2}{*}{ UP/DN } & -0.48 & -0.53 & -0.54 & -0.06 \\
& $(-3.72)$ & $(-3.17)$ & $(-2.25)$ & $(-0.31)$ \\
DN/UP & -1.01 & -1.12 & -1.07 & -0.07 \\
& $(-3.52)$ & $(-3.52)$ & $(-2.84)$ & $(-0.32)$ \\
DN/DN & 0.83 & 0.77 & 0.61 & -0.22 \\
& $(4.33)$ & $(3.45)$ & $(2.38)$ & $(-1.11)$ \\
\hline & & & & \\
\hline & Panel B: Time-series momentum returns sorted on IV and conditioned on market dynamics \\
\hline Market & Low IV & Med IV & High IV & 0.73 \\
\hline \multirow{2}{*}{ UP/UP } & 1.97 & 2.11 & 2.70 & $(1.51)$ \\
& $(4.33)$ & $(3.40)$ & $(3.51)$ & -0.98 \\
UP/DN & -1.57 & -2.27 & -2.55 & $(-1.96)$ \\
& $(-2.82)$ & $(-3.29)$ & $(-3.01)$ & -1.73 \\
DN/UP & -2.65 & -3.88 & -4.37 & $(-2.13)$ \\
& $(-4.3)$ & $(-4.05)$ & $(-3.52)$ & 0.78 \\
DN/DN & 2.84 & 3.37 & 3.62 & $(1.39)$ \\
\hline
\end{tabular}




\section{Table 8: Momentum returns, lagged and subsequent market states and sub-samples}

The table presents the cross-sectional (CS) and time-series (TS) average monthly momentum returns conditioned on market dynamics. Panel A reports momentum returns before the 2008 financial crisis (1990-2008) while Panel B reports momentum returns during and after the 2008 financial crisis (2008-2014). At the beginning of month $t+1$, we use the Nikkei225 Index returns over past 12 ( $t-11$ to $t)$ months and Nikkei225 Index subsequent returns over the holding period $t+1$ to define the market states. If lagged and subsequent market returns are positive (negative), the market state is defined as UP/UP (DN/DN). If lagged market returns are positive (negative), and subsequent market returns are negative (positive), then the market state is defined as UP/DN (DN/UP). For CS momentum returns, at the beginning of each month $t+1$, all stocks are sorted into deciles based on their lagged 6-month ( $t$-6 to $t-1)$ returns, and stocks with highest (lowest) 6-month lagged returns are bought (sold). These portfolios are held for 6 months ( $t+1$ to $t+6)$. For TS momentum returns, the same procedures are followed except that stocks are selected on their own performance. As in Jegadeesh and Titman (1993), we use the rebalanced portfolios. The table reports the average monthly returns of the loser and winner portfolios, momentum returns, and CAPM and Fama-French Alphas with $t$-statistics in the parentheses. The sample period ranges from January 1990 to December 2014.

\begin{tabular}{|c|c|c|c|c|c|c|c|c|}
\hline \multirow[b]{2}{*}{ Panel A: 1990-2007 } & \multicolumn{4}{|c|}{ CS Momentum Returns } & \multicolumn{4}{|c|}{ TS Momentum Returns } \\
\hline & UP/UP & UP/DN & DN/UP & $\mathrm{DN} / \mathrm{DN}$ & UP/UP & UP/DN & DN/UP & $\mathrm{DN} / \mathrm{DN}$ \\
\hline$N$ & 54 & 45 & 49 & 56 & 54 & 45 & 49 & 56 \\
\hline \multirow{2}{*}{ LOSER } & 2.64 & -2.94 & 7.05 & -6.24 & 1.90 & -1.88 & 6.31 & -5.91 \\
\hline & $(3.74)$ & $(-3.86)$ & $(5.14)$ & $(-10.46)$ & $(3.51)$ & $(-2.89)$ & $(4.32)$ & $(-6.87)$ \\
\hline \multirow[t]{2}{*}{ WINNER } & 5.00 & -4.48 & 4.49 & -3.53 & 3.81 & -4.51 & 2.19 & -2.53 \\
\hline & $(5.25)$ & $(-4.46)$ & $(6.68)$ & $(-6.52)$ & $(4.30)$ & $(-4.64)$ & $(4.47)$ & $(-6.24)$ \\
\hline \multirow[t]{2}{*}{ MOMENTUM RETURNS } & 2.36 & -1.53 & -2.56 & 2.70 & 1.91 & -2.62 & -4.12 & 3.39 \\
\hline & $(2.13)$ & $(-1.73)$ & $(-2.13)$ & $(4.25)$ & (2.59) & $(-3.12)$ & $(-3.43)$ & $(4.58)$ \\
\hline \multirow[t]{2}{*}{ CAPM ALPHA } & 2.81 & -1.94 & -1.99 & 2.09 & 2.78 & -3.42 & -3.02 & 2.20 \\
\hline & $(2.49)$ & $(-2.09)$ & $(-1.72)$ & $(3.25)$ & $(3.50)$ & $(-3.68)$ & $(-2.74)$ & $(3.05)$ \\
\hline \multirow[t]{2}{*}{ Fama-French (FF) ALPHA } & 2.76 & -1.50 & -1.80 & 2.58 & 2.71 & -3.41 & -3.05 & 2.04 \\
\hline & $(2.84)$ & $(-1.63)$ & $(-1.68)$ & $(4.16)$ & $(3.13)$ & $(-3.51)$ & $(-3.07)$ & $(3.22)$ \\
\hline Panel B: 2008-2014 & UP/UP & UP/DN & DN/UP & $\mathrm{DN} / \mathrm{DN}$ & UP/UP & UP/DN & DN/UP & DN/DN \\
\hline$N$ & 23 & 21 & 22 & 18 & 23 & 21 & 22 & 18 \\
\hline \multirow[t]{2}{*}{ LOSER } & 5.31 & -2.33 & 5.10 & -8.12 & 3.53 & -0.90 & 5.86 & -7.30 \\
\hline & $(5.58)$ & $(-2.20)$ & $(3.84)$ & $(-5.14)$ & $(5.1)$ & $(-1.20)$ & $(4.8)$ & $(-5.08)$ \\
\hline \multirow[t]{2}{*}{ WINNER } & 6.68 & -4.14 & 3.71 & -6.22 & 6.54 & -1.88 & 2.36 & -3.73 \\
\hline & $(5.60)$ & $(-4.59)$ & $(5.5)$ & $(-5.03)$ & (5.99) & $(-1.67)$ & $(4.72)$ & $(-5.53)$ \\
\hline \multirow[t]{2}{*}{ MOMENTUM RETURNS } & 1.38 & -1.81 & -1.39 & 1.90 & 3.01 & -0.99 & -3.49 & 3.57 \\
\hline & $(1.36)$ & $(-2.27)$ & $(-1.02)$ & $(1.77)$ & $(3.41)$ & $(-1.24)$ & $(-2.91)$ & $(3.01)$ \\
\hline \multirow[t]{2}{*}{ CAPM ALPHA } & 1.77 & -2.06 & -0.95 & 1.26 & 4.03 & -1.66 & -2.34 & 1.90 \\
\hline & $(1.72)$ & $(-2.7)$ & $(-0.71)$ & $(1.21)$ & $(4.08)$ & $(-1.95)$ & $(-2.12)$ & $(1.97)$ \\
\hline \multirow[t]{2}{*}{ Fama-French (FF) ALPHA } & 2.34 & -1.88 & -1.10 & 1.77 & 2.99 & -1.55 & -2.12 & 1.33 \\
\hline & $(2.30)$ & $(-2.04)$ & $(-0.78)$ & $(1.49)$ & $(2.95)$ & $(-1.91)$ & $(-1.89)$ & $(1.82)$ \\
\hline
\end{tabular}




\section{Table 9: Momentum returns, market dynamics and alternative holding periods}

The table presents the cross-sectional (CS) and time-series (TS) average monthly momentum returns for $k$-holding ( $k=3,9$ and 12) months conditioned on market dynamics. Panel A reports CS momentum returns while Panel B reports TS momentum returns. At the beginning of month $t+1$, we use the Nikkei225 Index returns over past 12 $(t-11$ to $t)$ months and Nikkei225 Index subsequent returns over the holding period $t+1$ to define the market states. If lagged and subsequent market returns are positive (negative), the market state is defined as UP/UP (DN/DN). If lagged market returns are positive (negative), and subsequent market returns are negative (positive), then the market state is defined as UP/DN (DN/UP). For CS momentum returns, at the beginning of each month $t+1$, all stocks are sorted into deciles based on their lagged 6-month ( $t-6$ to $t-1)$ returns, and stocks with highest (lowest) 6-month lagged returns are bought (sold). These portfolios are held for $k$ months. For TS momentum returns, the same procedures are followed except that stocks are selected on their own performance. (see section 2.B for a detailed description). As in Jegadeesh and Titman (1993), we use the rebalanced portfolios. The table reports the average monthly momentum returns with $t$-statistics in the parentheses. The sample period ranges from January 1990 to December 2014.

\begin{tabular}{lcccc}
\hline \multicolumn{5}{c}{ Panel A: CS momentum returns for $k$-holding $(k=3,9$ and 12) months } \\
\hline$K=3$ & UP/UP & UP/DN & DN/UP & DN/DN \\
\hline \multirow{4}{*}{$K=9$} & 1.63 & -1.70 & -2.79 & 2.68 \\
& $(1.93)$ & $(-2.25)$ & $(-2.43)$ & $(3.85)$ \\
$K=12$ & 2.04 & -1.57 & -1.66 & 2.21 \\
& $(2.69)$ & $(-2.58)$ & $(-1.96)$ & $(4.38)$ \\
& 1.45 & -1.60 & -1.17 & 1.60 \\
& $(2.25)$ & $(-2.73)$ & $(-1.50)$ & $(3.27)$ \\
\hline$K=3$ & & & DN/DN \\
\hline \multirow{4}{*}{$K=9$} & Panel B: TS momentum returns for $k(k=3,9$ and 12 months $)$ holding periods \\
& UP/UP & UP/DN & DN/UP & 3.05 \\
$K=12$ & 2.10 & -2.09 & -3.91 & $(4.21)$ \\
& $(3.24)$ & $(-3.07)$ & $(-3.98)$ & 3.50 \\
& 2.27 & -1.53 & -3.14 & $(5.86)$ \\
& $(4.08)$ & $(-3)$ & $(-3.86)$ & 3.00 \\
\end{tabular}

